\title{
Lasiodiplodia theobromae agente causal de la pudrición blanda de frutos de Artocarpus heterophyllus Lam. en Nayarit, México
}

\author{
María de Los Angeles Medina Tiznado ${ }^{1}$, Gregorio Luna Esquivel², Octavio Jhonathan Cambero Campos ${ }^{2}$, \\ Leobarda Guadalupe Ramírez Guerrero², Claudio Rios Velasco ${ }^{3}$
}

Resumen- Se recolectaron frutos de yaca (Artocarpus heterophyllus Lam.) con síntomas de pudrición blanda marrón, durante los periodos seco (mayo-junio, 2016) y lluvioso (agosto, 2016), en plantaciones de los municipios de San Blas y Compostela, Nayarit, México. El objetivo del estudio fue identificar al agente causal de la pudrición blanda de frutos precosecha. Se obtuvieron 150 disecciones de la zona de avance de la enfermedad a partir de 12 frutos y se sembraron en medio de cultivo papa-dextrosa-agar (PDA). Se aislaron cinco géneros de hongos (Colletotrichum sp., Aspergillus sp., Rhizopus sp., Lasiodiplodia sp. y Cunninghamella sp.), los cuales se inocularon sobre la epidermis de frutos de yaca aparentemente sanos mediante dos procedimientos (con y sin herida) bajo condiciones de laboratorio con segmentos de PDA micelial de $0.5 \mathrm{~cm}^{2} \mathrm{de}$ seis días de desarrollo. En las pruebas de patogenicidad Lasiodiplodia sp. fue el único hongo que causó los síntomas de pudrición blanda, expresados a los 5 y 6 días post-inoculación (dpi) en un $87.5 \%$ y $62.5 \%$ con y sin herida, respectivamente. De acuerdo con sus caracteres morfológicos y su secuencia genómica, el hongo patogénico fue identificado como Lasiodiplodia theobromae, siendo el primer reporte de este patógeno en frutos de yaca en Nayarit, México.

Términos para indexación: región ITS, pruebas de patogenicidad, identificación molecular, secuencia genómica, patógeno.

\section{Lasiodiplodia theobromae agente causal de podridão mole de frutas de Artocarpus heterophyllus Lam. em Nayarit, México}

Corresponding author: gollole@hotmail.com

Received: February 08, 2018 Accepted: March 09, 2018.

Copyright: All the contents of this journal, except where otherwise noted, is licensed under a Creative Commons Attribution License.

\section{(cc)) EY}

Resumo- Os frutos da Jaca foram recolhidos (Artocarpus heterophyllus Lam.) com sintomas de podridão mole castanho durante períodos de seca (Maio-Junho de 2016) e chuvoso (Agosto, 2016) em plantações dos municípios de San Blas e Compostela, Nayarit, México. O objetivo do estudo foi identificar o agente causal da podridão mole de frutos pré-colheita. 150 dissecções área progressão da doença foram obtidos a partir de 12 frutos e semeadas em meio de cultura de agar de batatadextrose médio (PDA). Cinco géneros de fungos (Colletotrichum sp., Aspergillus sp., Rhizopus sp., Lasiodiplodia spp. e Cunninghamella sp.) foram isoladas, que foram inoculadas sobre a epiderme de frutos de jaca aparentemente saudável por dois métodos (com e sem ferida) em condições de laboratório com segmentos de PDA micelial de $0,5 \mathrm{~cm}^{2}$ de seis dias de desenvolvimento. Nas testes de patogenicidade, Lasiodiplodia sp. foi a única fungo causador da podridão mole expressas em 5 e 6 dias após a inoculação (dpi) 87,5\% 62,5\% com e sem ferimento, respectivamente. De acordo com as suas características morfológicas e sequência genómica, o fungo patogénico foi identificado como Lasiodiplodia theobromae, o primeiro relatório de que este agente patogénico em jaca fruta em Nayarit, México.

Termos para indexação: região ITS, testes de patogenicidade, identificação molecular, sequência genómica, patógeno.

${ }^{1}$ Post degree on Agricultural, Biological Sciences, Autonomous University of Nayarit, Xalisco, Nayarit, Mexico. Km 9, Tepic-Compostela Highway, Xalisco, Nayarit, Mexico. P. C. 63155. E-mail: eleazar_225@hotmail.com

${ }^{2}$ Professor-Researcher of Post degree in Agricultural Biological Sciences-Academic Unit of Agriculture, Autonomous University of Nayarit. Km.9, Tepic-Compostela Highway, Xalisco, Nayarit, Mexico. P. C.63155.E-mail: gollole@hotmail.com, jhony695@gmail.com, leo.ram89@ hotmail.com

${ }^{3}$ Center for Research in Food and Development, AC, Cuauhtémoc Unit, Av. Río Concho s / n Industrial Park, City Cuauhtémoc, Chihuahua Mexico. P. C. 31570 E-mail: claudio.rios@ciad.mx 
La yaca (Artocarpus heterophyllus Lam.) es originaria de las selvas tropicales de India (APAARI, 2012) y se aprovecha principalmente el fruto (LOVE y PAULL, 2011). En México, Nayarit es el principal estado productor de yaca al concentrar el $90 \%$ de la superficie plantada destinando la mayor parte de la producción a los Estados Unidos de América (SIAP, 2016). En Nayarit el cultivo de yaca produce fruta todo el año (LUNA et al., 2013) y su producción es afectada por enfermedades fungosas dentro de las cuales destaca la pudrición blanda en la epidermis de los frutos que inicia con un amarillamiento en el pericarpio, aproximadamente un mes antes de que el fruto llegue a madurez fisiológica. Los patógenos asociados a la pudrición de frutos de yaca son Rhizopus stolonifer (Enrenb.) Vuill. en India (GHOSH et al., 2015) y Tailandia $(R$. artocarpi Racib. $=$ R. stolonifer) (APAARI, 2012). Nelson (2005) menciona que Rhizopus arrhizus A. Fisch. (=R. oryzae Went \& Prins. Geerl.) y R. stolonifer también son capaz de causar pudrición en frutos de yaca con pérdidas del 15 al $32 \%$ (GHOSH, 1994). Ni et al. (2008) y Rahman et al. (2015) reportaron a Lasiodiplodia theobromae (Pat.) Griffon \& Maubl. y Sclerotinia sclerotiorum (Lib.) de Bary en frutos de yaca en Taiwán y Bangladesh, respectivamente. En Nayarit, Ragazzo et al. (2011) reportaron a Aspergillus niger Tiegh. como el patógeno causante de la pudrición poscosecha de frutos de yaca. Por lo anterior, el objetivo de esta investigación fue identificar mediante caracteres morfológicos y moleculares el patógeno de la pudrición blanda en frutos de yaca en Nayarit, México. Los muestreos se realizaron en las localidades de El Llano y Las Varas en los municipios de San Blas y Compostela. Se recolectaron frutos con síntomas de pudrición blanda, se seccionó el tejido de la zona de avance de la enfermedad, se desinfectó con $\mathrm{NaClO}$ al $3 \%$ por $2 \mathrm{~min}$, se enjuagó con agua destilada estéril en tres tiempos por 2 min y se colocó en toallitas de papel estéril para su secado a temperatura ambiente, finalmente se sembraron en cajas de Petri (SYM $\left.{ }^{\circledR}\right)$ con medio de cultivo papa dextrosa agar (PDA-BIOXON $®)$ y se incubaron a $28^{\circ} \mathrm{C} \pm 2{ }^{\circ} \mathrm{C}$ por 7 días ${ }^{\circledR}$ ) (AGRIOS, 2005), una vez desarrollados los hongos, se purificaron mediante la técnica descrita por Manandhar et al. (1995) para obtener cultivos monospóricos y posteriormente realizar la identificación morfológica a nivel de género mediante claves taxonómicas de Barnett y Hunter (2006). La inoculación se realizó en frutos asintomáticos en estado de madurez fisiológica mediante dos procedimientos, el primero consistió en causar lesiones (heridas de $2 \mathrm{~cm}^{2}$ ) en el fruto y el segundo consistió en inocular a los frutos sobre el pericarpio (sin causarles heridas). El inóculo consistió en segmentos de PDA con micelio de $0.5 \mathrm{~cm}^{2}$ mientras que los testigos consistieron de segmentos de PDA sin inóculo infectivo. Los frutos inoculados se incubaron a $23{ }^{\circ} \mathrm{C}$ y $74 \%$ de humedad relativa, se revisaron diariamente y los que mostraron síntomas de pudrición se procesaron para el reaislamiento. Se describieron los caracteres morfológicos macroscópicos cualitativos y cuantitativos del hongo patógeno realizando preparaciones semipermanentes. La extracción de ADN se realizó por PCR a partir de un cultivo de 3 días de crecimiento en medio de cultivo sólido PDA a $28{ }^{\circ} \mathrm{C}$ mediante la técnica descrita por AHRENS y SEEMÜLLER (1992). Se amplificó la región espaciadora transcrita interna (ITS) del ADN utilizando los cebadores ITS5 (5'- TCCTCCGCTTATTGA TATGC- 3') e ITS4 (5'-TCCTCCGCTTATTGATATGC-3') (WHITE et al., 1990) y se secuenció. De los 150 fragmentos de tejido sembrados en PDA, se aislaron los géneros: Colletotrichum sp., Aspergillus sp., Cunninghamella sp., Rhizopus sp. y Lasiodiplodia sp., sin embargo, solo Lasiodiplodia sp. reprodujo el síntoma de pudrición blanda en el área inoculada (Fig. 1), a los 5 días post-inoculación (dpi) en $87.5 \%$ de los tejidos con herida y en tejido sin herida se manifestó a los 6 dpi en un $62.5 \%$, en ambos casos se presentó la pudrición total de los frutos a los 9 dpi. Los síntomas y el tiempo de aparición fue similar a lo reportado por Ni et al. (2008) en Taiwán en frutos de yaca, quienes a los 6 dpi con L. theobromae, los frutos con herida mostraron síntomas en el área inoculada, principalmente manchas amarillentas, que se tornaron de color café y finalmente adquirieron un color café marrón oscuro de aspecto húmedo y sobre ellas se observó el desarrollo de micelio y esporulación de color gris a negro. El crecimiento diario promedio de la pudrición con herida fue de $5.58 \mathrm{~cm}$ de longitud por $4.46 \mathrm{~cm}$ de ancho, los frutos inoculados sin herida de longitud creció $5.73 \mathrm{~cm}$ y de ancho $5.23 \mathrm{~cm}$. Algunas manchas alcanzaron un tamaño de $12 \mathrm{~cm}$ lineales en 4 días, mientras que Ni et al. (2008), reporta un tamaño de manchas de $10 \mathrm{~cm}$ en 5 días.

Lasiodiplodia theobromae mostró un crecimiento uniforme y continuo in vitro con un promedio de $4.6 \mathrm{~cm}$, del primer al quinto día, las colonias desarrollaron micelio algodonoso abundante de color blanco-grisáceo aéreo que se tornó gris oliváceo, el centro de la caja se observó un color gris oscuro mientras que al reverso fue grisáceo (1-3 días), después se tornó negro; a los 20 días se observaron conidiomas picnidiales. Los conidios jóvenes fueron ovales, hialinos y de paredes delgadas sin septos mientras que los conidios maduros mostraron un color marrón oscuro y de paredes gruesas con un tabique mediano y estriaciones longitudinales.

Haque et al. (2005) reportaron a esta enfermedad como el tizón de la hoja en yaca en Bangladesh causada por $L$. theobromae (=Botryodiplodia theobromae Pat.). En el Pacifico Sur de Asia se registró a L. theobromae ocasionando defoliación prematura de hojas y la enfermedad rosada en ramas junto con otras especies de Lasiodiplodia (APAARI, 2012). A nivel mundial ha sido registrado en diversos cultivos tales como fresa (Fragaria $x$ ananassa Dúchense) en Turquía (YILDIZ et al., 2014), pomelo (Citrus grandis L. Osbeck) en China (LUO et al., 
2011), naranja china (Fortunella margarita Lour. Swingle) en Taiwán (KO et al., 2004), aguacate (Persea americana Mill.) en Italia (GARIBALDI et al., 2012), mango (Mangifera indica L.) en Pakistán y Brasil (SHAHBAZ et al., 2009; MARQUES et al., 2013), rambután (Nephelium lappaceum L.) en Sri Lanka (SIVAKUMAR et al., 1997), papaya (Carica papaya L.) en Brasil (QUEIROZ et al., 1997), marañón (Anacardium occidentale L.) en Brasil (CARDOSO et al., 2002), longan (Dimocarpus longan L.) en Puerto Rico (SERRATO-DÍAZ et al., 2014), entre otros. En México, L. theobromae se ha reportado en cultivos frutícolas como zapote (Pouteria sapota (Jacq.) HE Moore y Stearn) (MORALES et al., 2008; VÁSQUEZ-LÓPEZ et al., 2009), vid (Vitis vinifera L.) (ÚRBEZ-TORRES et al., 2008), nuez (Carya illinoensis
Wood) (ALVIDREZ-VILLARREAL et al., 2 012), papaya (Carica papaya L.) (ROJO, 2013) y mango (Mangifera indica L.) (SANDOVAL-SÁNCHEZ et al., 2013). Con base a las pruebas de patogenicidad positiva, caracteres morfológicos y secuencia genómica en el GENBANK (NCBI, 2017), se obtuvo una homología del $99 \%$ con L. theobromae, (número de acceso KX462997.1: KM278132.1) por lo que se determinó que este patógeno es el agente causal de la pudrición blanda marrón de los frutos de yaca en Nayarit, México, siendo el primer reporte de este patógeno asociado a frutos de yaca en el país, además, de mostrar la capacidad de causar la enfermedad en frutos con o sin heridas.

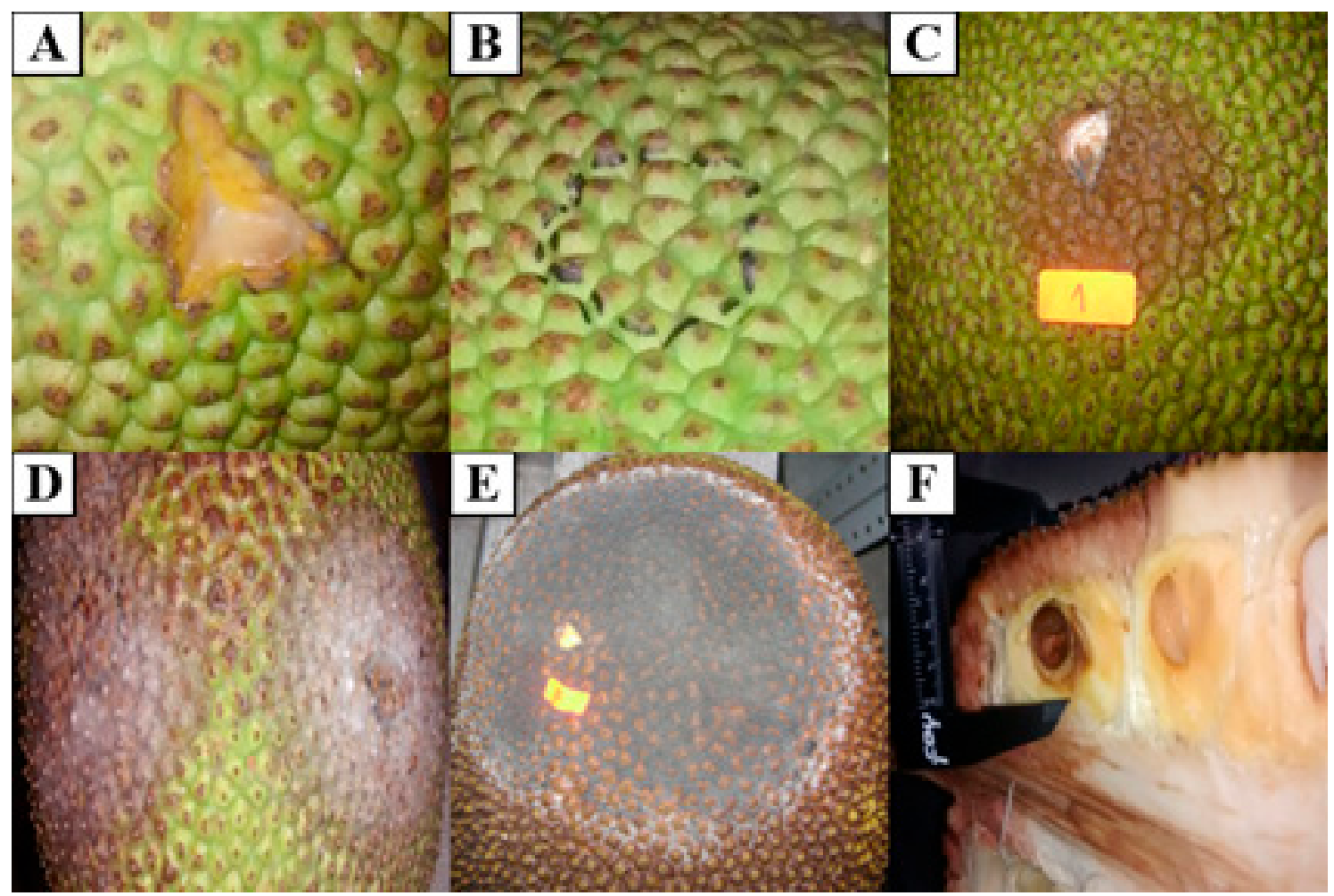

Figura 1- Síntomas de pudrición de frutos de yaca causados por Lasiodiplodia theobromae, A) Testigo con herida, B) Testigo sin herida, C) Pudrición marrón a partir del área inoculada con herida, D) Inicio de síntoma de la enfermedad a partir del área inoculada sin herida E) Pudrición completa del fruto y esporulación del patógeno F) Pudrición interna de fruto (zona de avance de la enfermedad).

\section{References}

AGRIOS, G. N. Plant pathology. $4^{\text {th }}$ ed. New York: Elsevier Academic Press, 2005. 922p.

AHRENS, U.; SEEMÜLLER, E. Detection de DNA of plant pathogenic mycoplasmalike organisms by polymerase chain reaction that amplifies a sequence of the 16S rRNA gene. Phytopathology, Palo Alto, v.82, p.828-832, 1992.
ALVIDREZ-VILLARREAL, R.; HERNÁNDEZCASTILLO, F.D.; GARCIA-MARTÍNEZ，O.; MENDOZA-VILLARREAL，R.; RODRÍGUEZHERRERA, R.; AGUILAR, C.N. Isolation and pathogenicity of fungi associated to ambrosia borer (Euplatypus segnis) found injuring pecan (Carya illinoensis) wood. Agricultural Sciences, Irving, v.3, p.405-416, 2012. 
APAARI- Asia-Pacific Association of agricultural Research Institutions. Jackfruit improvement in the Asia-Pacific Region a status report. Bangkok, 2012. $182 p$.

BARNETT, H.L.; HUNTER, B.B. Illustrated genera of imperfect fungi. $4^{\text {th }}$ ed. Minesota: APS Press, 2006. USA.

CARDOSO, J.E.; VIDAL, J.C.; SANTOS, A.D.; FREIRE, F.C.O.; VIANA, F.M.P. First report of black branch dieback of cashew caused by Lasiodiplodia theobromae in Brazil. Plant Disease, Pullman, v.86, n.5, p.558-558, 2002.

GARIBALDI, A.; BERTETTI, D.; AMATULLI, M. T.; CARDINALE, J.; GULLINO, M. L. First report of postharvest fruit rot in avocado (Persea americana) caused by Lasiodiplodia theobromae in Italy. Plant Disease, Pullman, v.96, n.3, p.460-460, 2012.

GHOSH, G.H. Studies on flowering and prevalence of fruit drop in jackfruit. Annual Report 1993-94. Gazipur: Horticulture Research Center, 1994. p.4-9.

GHOSH, R.; BARMAN, S.; MUKHOPADHYAY, A.; MANDAL, N. C. Biological control of fruit-rot of jackfruit by rhizobacteria and food grade lactic acid bacteria. Biological Control, Amsterdam, v.83, p.29-36, 2015.

HAQUE, M.M.; MRIDHA, M.A.U.; BHUIYAN, M.K.; HUDA, S.M.S.; UDDIN, M.B. Studies on the occurrence and severity of leaf blight of jackfruit (Artocarpus heterophyllus Lam.) caused by Botryodiplodia theobromae Pat. Journal of Mycopathological Research, Calcutta, v.43, n.1, p.91-94, 2005.

KO, W. H.; WANG, I. T.; ANN, P. J. Lasiodiplodia theobromae as a causal agent of kumquat dieback in Taiwán. Plant Disease, Pullman, v.88, n.12, p.1383-1383, 2004.

LOVE, K.; PAULL, E. R. Jackfruit. Fruits and nuts. Manoa: College of tropical Agriculture and Human Resources, University of Hawaii, 2011.

LUNA, E.G.; ALEJO, S.C.; RAMÍREZ, G.L.G.; ARÉVALO, G.M.L. La yaca (Artocarpus heterophyllus Lam.) un fruto de exportación. Agro Productividad, Texcoco, v.6 n.5, p.65-70, 2013.

LUO, M.; DONG, Z. Y.; BIN, S. Y.; LIN, J. T. First report of fruit rot disease on pomelo caused by Lasiodiplodia theobromae in China. Plant Disease, Pullman, v.95, n.9, p.1190-1190, 2011.
MANANDHAR, J. B.; HARTMAN G. L.; WANG, T. C. Conidial germination and appressorial formation of Collectotrichum capsici and C. gloeosporioides isolates from pepper. Plant Disease, Pullman, v.79 p.361-366, 1995.

MARQUÉS, M.W.; LIMA, N.B.; MORAIS JUNIOR, M.A.; BARBOSA, M.A.G.; SOUZA, B.O.; MICHEREFF, S.J.; PHILLIPS, A.J.L.; CÂMARA, M.P.S. Species of Lasiodiplodia associated with mango in Brazil. Fungal Diversity, Hong Kong, v.61, n.1, p.181-193, 2013.

MORALES, A.M.; HERNÁNDEZ, L.U.H.; OSORIO, R.O.; TEJACAL, I.A.; MARTÍNEZ, V.L.; BAÑOS, S.B.; SÁNCHEZ, D.G. Incidencia y severidad de Botryodiplodia theobromae en frutos de zapote mamey en Jalpa de Méndez, Tabasco, México. Revista Científica UDO Agrícola, Cumaná, v.8, n.1, p.29-32, 2008.

NCBI - National Center for Biotechnology Information. Gen Bank. 2012. Disponible em: <http://www.ncbi.nlm. nih.gov>. Acesso em: maio 2017.

NELSON, S. Rhizopus rot of jackfruit. Manoa: Cooperative Extensión Service, 2005. (Plant Disease, PD-29).

NI, H.F.; CHEN, R.S.; CHANG, S.F.; YANG, H.R. First report of Lasiodiplodia fruit rot of jackfruit in Taiwán. Plant Disease, Pullman, v.92, n.7, p.1137-1137, 2008.

QUEIROZ, F.; MUNIZ, M.; MENEZES, M. Podridão da haste do mamoeiro 'Sunrise Solo' causada por Botryodiplodia theobromae no Estado de Alagoas. Summa Phytopathologica, Botucatu, v.23, n.1, p.44-45, 1997.

RAGAZZO, S.J.A.; GUTIÉRREZ, E.A.; LUNA, S.G.; GÓMEZ, L.J.F.; CALDERÓN, S.M. Identificación molecular del hongo causante de la pudrición postcosecha de la jaca. Revista Mexicana de Micología, Mexico, v.34, p.9-15, 2011.

RAHMAN, M.M.E.; DEY, T.K.; HOSSAIN, D.M.; NONAKA, M.; HARADA, N. First report of white mould caused by Sclerotinia sclerotiorum on jackfruit. Australasian Plant Disease Notes, Collingwood, v.10, n.1, p.10, 2015.

ROJO, B.I. Lasiodiplodia theobromae, Colletotrichum gloeosporioides y Colletotrichum capsici asociadas a pudrición del pedúnculo y antracnosis en papaya (Carica papaya L.). 2013. 69 f. Tesis (Maestría) - Centro de Investigación en Alimentación y Desarrollo A.C. Unidad Culiacán, Culiacán, Sinaloa, 2013. 
SANDOVAL-SÁNCHEZ M.; NIETO-ÁNGEL, D.; SANDOVAL-ISLAS, J.S.; TÉLIZ-ORTIZ, D.; OROZCOSANTOS, M.; SILVA-ROJAS, H.V. Hongos asociados a pudrición del pedúnculo y muerte descendente del mango (Mangifera indica L.). Agrociencia, Montevideo, v.47, p.61-73, 2013.

SERRATO-DÍAZ, L.M.; RIVERA-VARGAS, L.I; GOENAGA, R.; FRENCH- MONAR, R.D. First report of Lasiodiplodia theobromae causing inflorescence blight and fruit rot of longan (Dimocarpus longan L.) in Puerto Rico. Plant Disease, Pullman, v.98, p.279, 2014.

SHAHBAZ, M.; IQBAL, Z. A. F. A. R.; SALEEM, A.; ANJUM, M. A. Association of Lasiodiplodia theobromae with different decline disorders in mango (Mangifera indica L.). Pakistan Journal Botany, Karachi, v.41, n.1, p.359-368, 2009.

SIAP - Servicio de Información Agroalimentaria y Pesquera. Cierre de la producción agrícola por cultivo. 2016. Disponível em: $\leq$ http://www.siap.sagarpa.gob.mx $>$. Acesso em: oct. 2016.

SIVAKUMAR，D.; WIJERATNAM，R.S.W.; WIJESUNDERA, R.L.C. ABEYSEKERA, M. Postharvest diseases of rambután (Nephelium lappaceum) in the western province. Journal of the National Science Council of Sri Lanka, Colombo, v.25, p.225-229, 1997.
ÚRBEZ-TORRES, J.R.; LEAVITT, G.M.; GUERRERO, J.C.; GUEVARA, J.; GUBLER, W.D. Identification and pathogenicity of Lasiodiplodia theobromae and Diplodia seriata, the causal agents of bot canker disease of grapevines in Mexico. Plant Disease, Pullman, v.92, p.519-529, 2008.

VÁSQUEZ-LÓPEZ, A.; MORA-AGUILERA, J. A.; CÁRDENAS-SORIANO, E.; TÉLIZ-ORTIZ, D. Etiología e histopatología de la muerte descendente de árboles de mamey (Pouteria sapota (Jacq.) HE Moore y Stearn) en el estado de Guerrero, México. Agrociencia, Montevideo, v.43, n.7, p.717-728, 2009.

WHITE, T.J.; BRUNS, T.; LEE, S.; TAYLOR, J. Amplification and direct sequencing of fungal ribosomal RNA genes for phylogenetics. In: INNIS, M.; GELFAND, D.; SNISKY, J.; WHITE, T. (Ed.). PCR protocols: a guide to methods and applications. San Diego: Academic Press, 1990. p.315-322.

YILDIZ, A.; BENLIOGLU, K.; BENLIOGLU, H.S. First report of strawberry dieback caused by Lasiodiplodia theobromae. Plant Disease, Pullman, v.98, n.11, p.15791579, 2014. 